\title{
Alexandra CÉALIS. Malaise agricole et politiques territoriales. Quelles réalités, quelles adéquations? Étude à partir du cas du canton de Nocé, siège du Parc naturel régional du Perche
}

\section{Nicolas Deffontaines}

\section{(2) OpenEdition}

\section{Journals}

Édition électronique

URL : http://journals.openedition.org/economierurale/5458

DOI : 10.4000/economierurale.5458

ISSN : 2105-2581

Éditeur

Société Française d'Économie Rurale (SFER)

Édition imprimée

Date de publication : 31 mars 2018

Pagination : 161-163

ISSN : 0013-0559

Référence électronique

Nicolas Deffontaines, «Alexandra CÉALIS. Malaise agricole et politiques territoriales. Quelles réalités, quelles adéquations ? Étude à partir du cas du canton de Nocé, siège du Parc naturel régional du Perche », Économie rurale [En ligne], 363 | janvier-mars 2018, mis en ligne le 31 mars 2018, consulté le 24 septembre 2020. URL : http://journals.openedition.org/economierurale/5458 ; DOI : https://doi.org/ 10.4000/economierurale. 5458 
Alexandra CÉALIS

\section{Malaise agricole} et politiques territoriales.

Quelles réalités, quelles adéquations ? Étude à partir du cas du canton de Nocé, siège du Parc naturel régional du Perche

Paris, L'Harmattan, 2016, 202 p.

F ormée à l'ethnologie et à la sociologie comparative, Alexandra Céalis propose dans cet ouvrage une analyse du malaise des agriculteurs à partir d'une entrée à la fois locale et institutionnelle, à savoir le rôle que peuvent jouer les politiques territoriales menées par une structure de Pays et un Parc naturel régional en matière de sentiments de disqualification et de perte de sens du métier éprouvés par nombre d'agriculteurs. Sa méthode qualitative, par observation des dispositifs d'accompagnement et d'encadrement des agriculteurs ainsi que par entretiens semi-directifs auprès de ces professionnels, fait en effet émerger l'expression d'un malaise latent parmi eux. Certaines franges d'agriculteurs se sentent exclues des conceptions portées par ces politiques territoriales. Pourquoi un tel malaise apparaît-il, tout particulièrement avec le Parc naturel régional, alors que ce territoire de projet n'a pas de prise sur la définition des politiques agricoles à l'échelle nationale, voire européenne?

Pour tâcher de le comprendre, I'auteure restitue d'abord minutieusement le contexte de l'enquête. Le Perche se caractérise par deux traits : une forte présence de résidences secondaires, d'une part, liée notamment à sa proximité géographique avec Paris, qui peut produire des tensions entre autochtones et allochtones; un faible taux d'accroissement démographique et un relatif vieillissement de la population, d'autre part, qui poussent les politiques territoriales à mettre l'accent sur l'arrivée de nouveaux arrivants, a fortiori de jeunes actifs. Dans cette optique, les politiques territoriales promeuvent une image essentialisée du Perche, celle d'un pays bocager fondé sur l'élevage. En résumé, le Perche doit se rattacher pleinement à la figure de la " Normandie verte ".

Or l'auteure montre par un détour historique très instructif que cette soidisant tradition paysagère n'est qu'une pure invention, apparue seulement à partir des années 1930 à l'échelle du Perche. Ce n'est pas tant la tendance au retour massif des labours des dernières décennies qui constitue une rupture que son inscription dans un paysage remembré, qui menace le bocage par l'agrandissement des parcelles et l'arrachage de haies. C'est donc l'intensification qui apparaît pour les institutions étudiées dans cet ouvrage comme un problème. Comment se retrouve-t-il posé ainsi ?

Deux mécanismes essentiels jouent. D'une part, en se voyant confier la mise en place des mesures agro-environnementales - émanation du second pilier de la PAC, le Parc naturel régional se trouve impliqué dans la question du développement durable en matière de pratiques agricoles. D'autre part, l'objectif d'attractivité du territoire à l'égard de populations urbaines - tout particulièrement franciliennes - " en quête de campagne, de qualité de vie, de bons produits... " enjoint le Parc et le Pays à tâcher de " mettre sous cloche » le paysage bocager.

Il faut compter aussi sur la concurrence avec les autres institutions en charge des questions agricoles sur le territoire pour comprendre un tel " choix " de la part du Pays et du PNR. La Chambre d'agriculture entend garder sa prérogative en matière d'installation des agriculteurs, et relègue le rôle du Parc dans ce domaine aux seuls circuits courts. C'est tout cet environnement institutionnel que l'auteur restitue dans le chapitre 3 pour mieux éclairer la façon dont se construisent de 
telles politiques territoriales. Localisée, l'analyse n'oublie pas de montrer par ailleurs les forces de longue distance qui contraignent et limitent leur pouvoir d'action.

De tous ces éléments, il résulte une tension très forte entre une "promotion touristique " et une réalité tout autre de la vie des agriculteurs, pour lesquels la question de la compétitivité économique sur des marchés globalisés leur est rappelée en permanence. Pour mieux rendre compte de son rôle structurant, I'auteure se fonde sur plusieurs couples d'oppositions qui signalent la confusion dans laquelle se trouvent placés les agriculteurs : ambition de nourrir le monde défendue par les agriculteurs dits "conventionnels" contre l'accent mis sur l'alimentation à l'échelle d'un territoire pour les adeptes des circuits courts, temps court des réglementations contre temps long des exploitations, discours manichéen relayé par les médias qui tend à opposer les "bons bios " et les conventionnels construits comme de véritables "délinquants de l'environnement ", vision patrimoniale du territoire à laquelle répond une conception entrepreneuriale de l'activité agricole... Tout se passe comme si deux camps que tout oppose se dessinaient. Le "nous » des agriculteurs conventionnels rejette le « eux » auquel le Parc se voit associé dans les esprits. "II y a un fossé entre le Parc et nous ", témoigne ainsi un agriculteur interviewé. Notons au passage que le Pays échappe à ce schéma, simple reflet de sa quasi-éviction des questions agricoles.

En conclusion de l'ouvrage, l'auteure n'hésite pas à qualifier cette production politique du Perche de « sorte de colonisation à la fois conceptuelle et humaine du territoire " (p. 175). On comprend alors à quel point certains agriculteurs peinent à trouver leur place dans le territoire, à se sentir reconnus socialement, voire à donner du sens à leur activité agricole. L'étude de l'expression de leur malaise qui parachève l'ouvrage peut se résumer autour de trois thèmes. Les agriculteurs éprouvent un sentiment de dépossession du métier, d'abord, sous l'effet des multiples réglementations qui encadrent leur activité. Leur indépendance statutaire-valeur cardinale de la profession - se voit malmenée par la sédimentation des instances de contrôle. Le " maquis institutionnel » décrit dans la première partie de l'ouvrage participe du malaise agricole en les soumettant en permanence à des injonctions contradictoires. Ces derniers ressentent une disqualification de leurs savoirs, ensuite, par des prescriptions qui sont parfois vécues comme une obligation à réapprendre leur métier. Ils expriment enfin le sentiment d'avoir été trahis par les institutions d'encadrement et les politiques agricoles, ayant joué le jeu de la modernisation pour se trouver finalement condamnés par la société civile. À ce propos, les pages Facebook et autres sites Internet tenus par des particuliers - tels que "Rêve de Beauce " ou "Stop pollution Orne »-forment de "nouveaux organes de contrôle citoyens " qui intensifient ce triptyque dépossession-disqualification des savoirs-sentiment de trahison.

Un des mérites de l'ouvrage est d'éviter le biais de la monographie d'institution en donnant la parole à ceux qui tendent à être éloignés des dispositifs mis en place, à leur donner une place centrale dans l'analyse, en résumé à dévoiler tout ce que la scène relègue dans les coulisses. On regrettera néanmoins que ce chapitre quatre centré sur l'expression du malaise agricole n'arrive que tardivement et ne soit pas davantage étoffé. II reste que cette enquête éclaire de façon originale la relation finalement peu connue entre les agriculteurs et les acteurs territoriaux que sont les structures de pays et les parcs naturels régionaux, réflexion fondamentale tant cette dernière peut s'avérer à bien des égards conflictuelle ; en témoignent par exemple, en d'autres lieux, la vive opposition des agriculteurs du Châtillonnais (Côte-d'Or) à la 
création d'un Parc naturel national sur le territoire du même nom ${ }^{1}$, ou encore la manifestation violente d'agriculteurs à la Maison du Parc naturel régional du Morvan² à Saint-Brisson (Nièvre).

Nicolas DEFFONTAINES INRA-CESAER
1. «Futur Parc national : les opposants font entendre leur colère, AG annulée », Bien public, 28 février 2017, http://www.bienpublic.com/editionhaute-cote-d-or/2017/02/27/futur-parc-nationalles-agriculteurs-font-entendre-leur colere-a-montigny-sur-aube.
2. «Le coup de colère des agriculteurs », Le Journal de Saône-et-Loire, 18 septembre 2013. 